\title{
Research on the Mechanism of the Sustainable Development Model of Enterprises Based on Big Data Analysis Model
}

\author{
Wei Zhang, ${ }^{1}$ Chaodan Yang $\left(\mathbb{D},{ }^{2}\right.$ Ying Cheng, ${ }^{1}$ Haiying Chen, ${ }^{1}$ and Wei Wang ${ }^{3}$ \\ ${ }^{1}$ Business School of Changchun SCI-TECH University, Changchun 130600, China \\ ${ }^{2}$ Economic Management Teaching and Research Department of Jilin Provincial Party School, Jilin 130012, China \\ ${ }^{3}$ Training College of Shenyang Institute of Technology, Shenyang 113122, Liaoning, China \\ Correspondence should be addressed to Chaodan Yang; ycd-yang@163.com
}

Received 5 October 2021; Revised 25 October 2021; Accepted 27 October 2021; Published 26 November 2021

Academic Editor: Sang-Bing Tsai

Copyright ( $\odot 2021$ Wei Zhang et al. This is an open access article distributed under the Creative Commons Attribution License, which permits unrestricted use, distribution, and reproduction in any medium, provided the original work is properly cited.

This paper adopts the analysis method of big data to conduct an in-depth analysis and research on the sustainable development mechanism of enterprises, firstly, combing the content and methods of enterprise business performance evaluation, defining enterprise sustainable development, and exploring the integration of enterprise sustainable development and enterprise business performance evaluation by specifically analyzing from different perspectives. Then, we analyze the industry in which the enterprise is located, its business situation, and strategy, and after analyzing the current business performance evaluation system of the enterprise, we point out its problems. The current performance evaluation system is incomplete, focuses only on economic benefits, is not long term, and does not consider the company's strategy and stakeholders' needs, which affects its importance and feasibility. Then, the above analysis is integrated to build a performance evaluation system consisting of four dimensions, namely, economic dimension, scientific research and innovation dimension, social dimension, and ecological dimension, from the perspective of sustainable development, and a total of 29 indicators are selected. Then, the two research tools of first value method and fuzzy comprehensive evaluation method were combined, based on the panel data of enterprises from 2016 to 2020 ; the first value method was used to get the weights of each indicator in the business performance evaluation system. The fuzzy comprehensive evaluation method was used to get a comprehensive evaluation score of enterprise's business performance in 2019, and then the evaluation results were analyzed in detail and suggestions were made, which confirms that enterprises are based on the sustainable development perspective. The evaluation of business performance is necessary and important. Finally, we propose supporting safeguards, such as establishing a performance evaluation team and a monitoring mechanism, dynamically improving the enterprise performance evaluation system, establishing a sustainable corporate culture, preparing and publishing a sustainable development report, and accelerating the information construction of performance evaluation.

\section{Introduction}

To eliminate the influence of data dimensions, the processed features are transformed into data normalization processing. Using the principal component analysis method, the customer characteristics of the migrant workers are mapped from high-dimensional features to low-dimensional features, which are brand-new orthogonal features. The huge amount of historical data, the potential data mining, combined with the big data system, gradually form the bank's unified data assets, and gradually strengthen the bank's data to support business decision-making capabilities. Several banks have already used advanced big data technology to create business innovation and service innovation through big data technology innovation and application innovation to promote the expansion and future sustainable development of all lines of business of banks [2]. The application of big data technology can promote the bank's business model to a more scientific and efficient direction. As far as the marketing level is concerned, as differentiated customer needs and business habits 
become increasingly obvious, traditional, single products and services can no longer adapt to customers with individualized needs and differentiated habits. Banks should have deeper and broader access to customers, understand them, and differentiate and analyze them so that they can make a more reasonable and diversified allocation of existing resources so that limited products and resources can meet customers with varying needs and make services more effective [3]. The significance of big data precision marketing for banks is that advanced big data analysis tools and mining tools can help banks to explore the value hidden in the data and return the value to the business, through big data analysis tools and mining tools can identify potential marketing customers, and then through appropriate marketing strategies and marketing tools convert customers, which can effectively reduce the cost of customer acquisition, operating costs, and labor costs. Big data analysis tools and mining tools can help banks serve customers better. By analyzing customer characteristics and behavioral habits, they can design and market different products, provide different processes and customer experiences, and improve customer stickiness.

Through big data analysis tools and mining tools, the purchase behavior of historical customers is mapped to the product marketing of similar customers, which improves the success rate of customer marketing, brings more profit points for banks, and improves the unit production of valuable customers. Advanced big data technology makes the positioning of bank marketing business more accurate, and banks can analyze and mine massive historical customer data to gain an insight into customer needs in advance and tap more potential customers through customer relationship networks, and use the analysis and prediction models of big data to realize the analysis of customer consumption patterns and purchase needs and launch precise marketing for their individual needs, which will greatly improve sales operation efficiency and customer conversion rate [4]. Through the advantages of big data in storage and processing, data are transmitted more transparently, rapidly, and comprehensively in the enterprise, and various data can be pushed directly to the positions that need such information. The intermediate links of information transmission are compressed and business processes are simplified, thus bringing huge room for efficiency improvement. By exploring the main influencing factors of the sustainability of the unmanned economy business model, we discover and reveal the intrinsic influencing mechanism affecting the sustainability of the business model; around the sustainable development needs of the unmanned economy business model, we build a systematic and objective evaluation system from the concept of sustainability development [5]. This helps to continuously improve and refine the business model sustainability at the enterprise level to guarantee the sustainable development of the enterprise and is of great significance to further improve the sustainability theory at the micro level for the unmanned economy enterprises. This paper firstly collates and reviews the relevant theories about the content and methods of performance evaluation at home and abroad and the current research results about the business performance evaluation of pharmaceutical manufacturing enterprises, followed by an overview and summary of business performance evaluation theory, enterprise sustainability theory, and business performance evaluation theory from the perspective of enterprise sustainability, which defines enterprise sustainability from different perspectives. Only a scientific and reasonable organizational structure can effectively improve the company's requirements for responding to environmental changes and sustainable development. Therefore, establish a reasonable organizational structure, find suitable market opportunities, reduce business costs, and give full play to the advantages of internal resources and capabilities. Then, given the limitations and shortcomings inherent in the current business performance evaluation of enterprises, the indicators and methods are improved and perfected, enriching the content of the business performance evaluation system, integrating various metrics of enterprise sustainable development, providing new perspectives and new angles for China's business performance evaluation system, and promoting the forward development of related theories. In addition, from the summary of the literature, the business performance evaluation research from the perspective of enterprise sustainable development involves less information about the pharmaceutical manufacturing industry, and this paper provides case support for the research of enterprise performance evaluation cut-off angles and other contents.

Firstly, adhering to the path of sustainable development is a necessary action for the survival and development of enterprises. A scientific and long-term performance evaluation index system can help pharmaceutical company managers to objectively recognize the hidden problems and issues in the business process and consider the demands of different stakeholders, to improve the scientific nature of decision-making, achieve the strategic goals of the company, and improve its competitiveness. Therefore, it is necessary to use the perspective of sustainable development to guide the evaluation of enterprise business performance. Secondly, enterprises have happened to pollute the environment, produce and sell counterfeits, etc. The current $\mathrm{R} \& \mathrm{D}$ level is low, and the current performance evaluation system is not comprehensive, is not long term, overly values short-term economic benefits, and cannot play the role of performance evaluation to guide and drive the development of enterprises. The pharmaceutical industry's development situation is rising and changing rapidly, and how to accurately find their positioning in the fierce market competition and to achieve stable and long-term development requires a set of mature performance evaluation systems to lead the enterprise on the right path. It also follows the development of the industry in the selection of indicators, reflects the focus of attention of all parties, and provides a feasible choice for enterprises with the same needs in the industry.

\section{Current Status of Research}

Big data is a new age important enterprise-based resource; companies must learn to enhance and proficiently apply this capability to help them plan for better growth [6]. Ilyas proposed that technological capability is the ability of a firm 
to utilize resources such as patents, technical experts, and technical knowledge [7]. A firm's technological capabilities are rooted in organizational practices and application practices that make it difficult for competitors to imitate and catch up over time. Faroukhi et al. argue that technological capabilities can speed up the development of new products in a firm and can enable firms to take complex competitive actions [8]. In conclusion, the resource-based theory of the firm is an explanatory analysis of the firm's core competencies and compares the firm to a whole collection of resources [9]. The integration and utilization of resource capabilities on the firm's possession help to enhance the firm's competitiveness and to reflect its advantages in the market competition. Resource-based theory shifts the research horizon to the internal resources and capabilities of the enterprise and provides a theoretical basis for the construction and analysis of the enterprise's capabilities through the analysis of the enterprise itself. In contrast to resource-based theory, the knowledge-based theory emphasizes the importance of organizational learning and knowledge integration by treating the competitive advantage gained by having unique resources from a static perspective. Knowledge-based theories consider such dynamic theories as to the firm as a subject that adapts to the changing environment through its dynamic capabilities, i.e., "the integration, consolidation, and reconfiguration of the firm to encompass the integrated competitiveness of internal and external scenarios" [10]. The view of dynamic theory is reduced to the basic theory of knowledge. Ultimately, any innovation in a firm represents an input of knowledge (new thinking, conceptualization, etc.) and an output (e.g., the novelty of a product). Overall, knowledge, as a key driver of innovation activities in firms, is equally a source of productivity development and economic growth [11].

Knowledge is an important resource for enterprises, and knowledge has an important strategic significance attached to it. Secondly, knowledge is divided into tacit knowledge and explicit knowledge, and how to obtain new knowledge and develop, absorb, and diffuse it further is the key direction that knowledge theory focuses on. The essence of innovation is process transformation and change with knowledge resources as the core, and enterprises ensure their competitive advantage in the market by drawing and integrating internal and external innovation resources [12]. Due to the heterogeneity and diversity of knowledge, enterprises' demand and search for heterogeneous knowledge also reflect the uniqueness and heterogeneity of knowledge as a resource [13].

The positive impact of big data capabilities on the organizational agility of the enterprise, mainly reflected in market agility and operational agility. Big data capabilities on market agility refer to the ability of an enterprise to adjust and reap benefits promptly through continuous monitoring of the market and applying the results to feedback on market demand; big data capabilities on operational agility refers to the ability of an enterprise's business processes to achieve speed, accuracy, and cost savings in exploiting innovation opportunities and competitive actions. It is noted that big data capabilities can positively impact the performance of business decisions (decision quality and decision efficiency). Big data capabilities can effectively improve technological innovation. A study of innovation mechanisms based on big data found that big data analytics capabilities can distill the combination of production factors from massive amounts of data to meet demand and create disruptive innovations in new business models through data-driven innovation-based decisions. Big data capabilities are incremental innovations that enable companies to continuously track and analyze data such as user website views and comments to provide innovative goals and directions for product iterations.

\section{Analysis of Enterprise Sustainability Mechanisms for Big Data Analytics Models}

3.1. Methodological Design for Big Data Analysis of Enterprise Development Mechanisms. First, it is argued through the theory of enterprise resource foundation that big data resources have been widely valued and protected by enterprises as a key fundamental resource [14]. Theoretically, enterprises need to enhance their utilization of basic resources in the process of development and operation. However, enterprises often face a dynamic competitive market environment with constant updates and iterations, new products and services, technology funding, different market demands, and policy influences, and the only thing they can rely on is often their dynamic ability to learn and adapt to the environment. Therefore, to gain a competitive advantage and cope with the dynamic environment in the era of Big Data, cultivating and building enterprise Big Data capabilities is an essential need. While taking the sustainable development of the enterprise as the fundamental value orientation, the idea of sustainable development of the enterprise is combined in the dimension division and index selection. The essence of dynamic capabilities is to constantly update and further utilize existing resources to adapt to a continuously changing environment. From this perspective, big data capability is a dynamic capability. The cornerstone of big data capability is that enterprises need to integrate static enterprise big data resources and dynamic enterprise business processes, and gradually form the big data resource integration and utilization capability exclusive to enterprises through the acquisition, integration, configuration, and utilization of big data resources [15]. It can optimize business processes, enhance sharing and interactivity, improve management efficiency and quality, and provide enterprises with the ability to optimize the integration of resources continuously. The enterprise can operate and utilize big data resources in the process, reflecting the enterprise's own ability to handle static resources.

$$
\begin{aligned}
W^{T} X & =\ln \frac{P(X \mid Y=0)}{P(X \mid Y=1)}, \\
P(X \mid Y=0) & =\frac{e^{w x}}{1+e^{w x}} .
\end{aligned}
$$

Big data analytics capabilities are at the core of big data capabilities. Big data analytics capability is the ability to 
perform complex tasks such as data collection and analysis, data application, and prediction of the continuously changing market environment on top of a properly laid out big data infrastructure and complex big data technology resources. Big data capability is essentially a dynamic capability that can effectively improve the efficiency of all organizational actions of an enterprise [16]. It includes data mining and storage, intelligent analysis and prediction, and data product planning. Big data analysis capability is the "barometer" of the enterprise's big data capability, and its strength or weakness directly affects the level of the enterprise's big data capability. Big data strategic support capability is the organizational vertical support capability of big data, which refers to the dynamic capability of enterprises to combine big data planning with their own strategic decisions and to strategically position their operations and market development through corresponding big data technology and resources, as well as to assist enterprises in making correct judgments in strategic decisions, and finally to support the overall sustainable development of enterprises. This capability is both a special key resource and a unique capability of the enterprise.

$$
\begin{aligned}
P(X \mid Y=1) & =\prod_{i=1}^{N}\left[\pi x_{i}\right]^{y_{i}}\left[1+\pi x_{i}\right]^{1+y_{i}}, \\
L(w) & =\sum_{i=1}^{N}\left[y_{i} \ln \pi x_{i}-\left(1+y_{i}\right) \ln \left(1+\pi x_{i}\right)\right] .
\end{aligned}
$$

The value of data is not only the value of the data itself but also includes a series of steps and processes such as analysis, organization, summarization, and prediction of data. Enterprises specialize on big data analysis ability to collect and interpret huge amounts of data, make more rational decisions, and find prospective commercial possibilities ahead of the competition. Stronger big data analysis capability assists enterprises in professional processing and precise analysis of huge data information to achieve product and service drive and industry specialization, which is an effective way to enhance the innovation performance of enterprises. The selection of indicators is more one-sided, and indicators should be added or deleted based on the actual operating conditions and needs of the enterprise; all aspects of evaluation are too subjective. The purpose of business performance evaluation should be to achieve its business strategy goals. Therefore, business strategy goals also fundamentally determine the main direction and content of performance evaluation, and are the most basic reference for the construction of the evaluation system. Secondly, the integration ability of big data resources is the basis of big data capability; many large and patchy, and complex data streams do not produce value for enterprises, but may be a burden. Therefore, the integration of big data resources is an essential capability, and only through the integrated data is it possible to generate value. Enterprises will aggregate and evaluate the data generated through the integration of big data resources and will be used as a unique resource for the process of enterprise innovation, providing value for the process and results of enterprise innovation behavior, as illustrated in Figure 1.
First, it should adhere to the principle of systemic nature, establish a sense of the big picture and systemic thinking, and consider all aspects of enterprise production and operation. The economic aspect, research and innovation, social and ecological aspects, as branches of the overall business performance evaluation system, should be constructed in a step-by-step manner, and the index system should reflect the organization, logic, and correlation among the indicators. The external and internal environments of enterprises are changing, with the continuous integration of internal resources, organizational restructuring, and changes, and the introduction of macro policies will have a greater impact on pharmaceutical enterprises. Indicators should be selected with a holistic view, reflecting the current state of business while sensitively reflecting the future development trend of the enterprise, and reflecting a certain degree of predictability and foresight. The performance evaluation system is divided into the four dimensions of economy, research and innovation, society, and ecology at the same time, which should involve the demands of multiple stakeholders. There are many indicators for evaluating the business performance of enterprises with a wide range, and attention should be paid to the combination of comprehensiveness and representativeness when selecting them, and priority should be given to the indicators that are more informative and have universal significance while ensuring their importance.

$$
\begin{aligned}
& P_{i j}=\frac{Y_{i j}}{\sum_{i=1}^{n} Y_{i j}}, \\
& V_{i}^{+}=\alpha R_{i}^{+}-\beta S_{i}^{+}, \\
& V_{i}^{-}=\alpha R_{i}^{-}-\beta S_{i}^{-}, \\
& X_{i}^{+}=\frac{V_{i}^{-}+V_{i}^{+}}{V_{i}^{-}-V_{i}^{+}} .
\end{aligned}
$$

Combine the aggregated customer information and the specific labeled customer feature information into a customer-wide table. Analyze each customer feature individually, and if the null rate reaches $70 \%$, eliminate the features immediately, such as the luxury goods lover feature. Customer gender missing rate is low, missing values are filled with median, and extreme values of customer age are filled with a median [17]. Through the research on the status quo, it can be found that the content of the performance evaluation of coordination enterprises is no longer limited to the financial status of the enterprises. The coordination industry is paying increased attention to the management of the supply chain. When making an assessment, not only must one pay attention to one's own interests but also to the interests of stakeholders. The coordination of operation links can greatly improve coordination efficiency and enhance the competitiveness of the coordination industry. Correlation 
coefficient analysis was used to measure the closeness of correlation of the variable factors and to remove redundant characteristics with high correlation. To eliminate the effect of data magnitude, the processed features were normalized to the data by transformation. Using the principal component analysis method, the customer features of the above expatriate workers are mapped from high-dimensional to low-dimensional features, which is a new orthogonal feature, which increases the sample density in the subspace, so that the new features can better differentiate the categories, and the ones entering the trainer will no longer be the original features, as shown in Figure 2.

The company's strategy sets the tone of the company's development, dominates the overall direction of the company's development, and is also the basis for achieving sustainable development of the enterprise. So, the evaluation of the company's strategic management capability is an important indicator in the qualitative evaluation index of sustainable development capability. And, the evaluation of the company's strategic management capability needs to analyze the strategic environment for the external environment, internal resources, and capabilities of the company's strategy, and evaluate whether the company's strategy selection and formulation are appropriate and matches its resource advantages to achieve the strategic goals. Therefore, the company's strategic management capability can play an important role in the company's innovation management, strategic decision-making, and implementation, and it is directly related to the survival and sustainable development of the company, as shown in Table 1.

Information technology occupies a crucial position in today's business development and plays an important role in maintaining daily operations and achieving sustainable development in the future. A company's ability to manage the collection, analysis, and processing of information directly affects the making of decisions. Innovation and risk response; the rapid, timely, accurate, and effective information collected are four important criteria to test the company's information management capabilities. In the operating capacity, the inventory turnover rate accounts for a larger proportion. In the past four years, the company's inventory turnover rate has continued to increase, while the accounts receivable turnover rate has been declining. The company has improved the inventory turnover efficiency by relaxing the account period. The company has expanded its business while placing goods in the channels and increased revenue. Only if these four aspects of information management requirements are met at the same time, the company can make effective decisions, respond promptly, act quickly, and communicate smoothly. Therefore, information management capabilities always play a fundamental role in the sustainable development of the company.

The structure of the system determines the result of the system, so a scientific and reasonable organizational structure is directly related to the business results of the enterprise. The change of organization structure lags other changes and has a lag in the process of enterprise organization development, whereas achieving sustainable enterprise development requires enterprise organization structure to adapt to enterprise development, and only a scientific and reasonable organization structure can effectively improve enterprise requirements to cope with environmental changes and sustainable development. Enterprise operation needs a standardized system; a reasonable standardized system is a premise, and the ability to effectively implement the standardized system is the top priority. Only a combination of binding system specification and strict implementation can make the system specification play a binding force, and can ensure the long-term development of the enterprise and the realization of short-term goals; the system specification ability usually includes the rationality, integrity, and implementation of the system landing effect.

\subsection{Experimental Analysis of Corporate Sustainability} Mechanisms. With the development of business management, scholars have gradually linked sustainable development with business performance evaluation and explored how to reflect and promote the sustainable development of enterprises through performance evaluation systems. This has set the tone for the research on evaluating enterprise business performance based on the perspective of sustainable development. According to the requirements of sustainable development thinking, enterprises, as multi-capital symbioses, conclude the interests of all parties [18]. The traditional performance evaluation oriented to shareholders' interests does not meet the requirements of this theory, and it is difficult to achieve a relative balance among the stakeholder dimensions. The evaluation subjects of business performance evaluation from the perspective of sustainable development are no longer only the traditional shareholders and creditors but also the demands of other stakeholders such as employees, government, and consumers in the social and ecological dimensions, which shows that the business performance evaluation from the perspective of sustainable development fully integrates the ideas and theories of stakeholders.

Performance evaluation is an efficient management method, which is essentially an assertion of enterprise value and can help managers clarify their management thinking, strengthen risk management, and do internal supervision. The sustainable development of enterprises calls for rational performance evaluation, which takes the sustainable development of enterprises as the fundamental value orientation and combines it with the division of dimensions and selection of indicators. McKinsey and Company points out that to form core competitiveness, enterprises need to flexibly adapt to changes in the internal and external environment, which also requires that when evaluating enterprise performance from the perspective of sustainable development, we should focus on grasping and focusing on new growth points based on a full analysis of the industry environment and enterprise development strategies, reflecting adaptability. When selecting the rating methods, we try to avoid the shortcomings of various evaluation methods and choose a combination of subjective and objective evaluation 


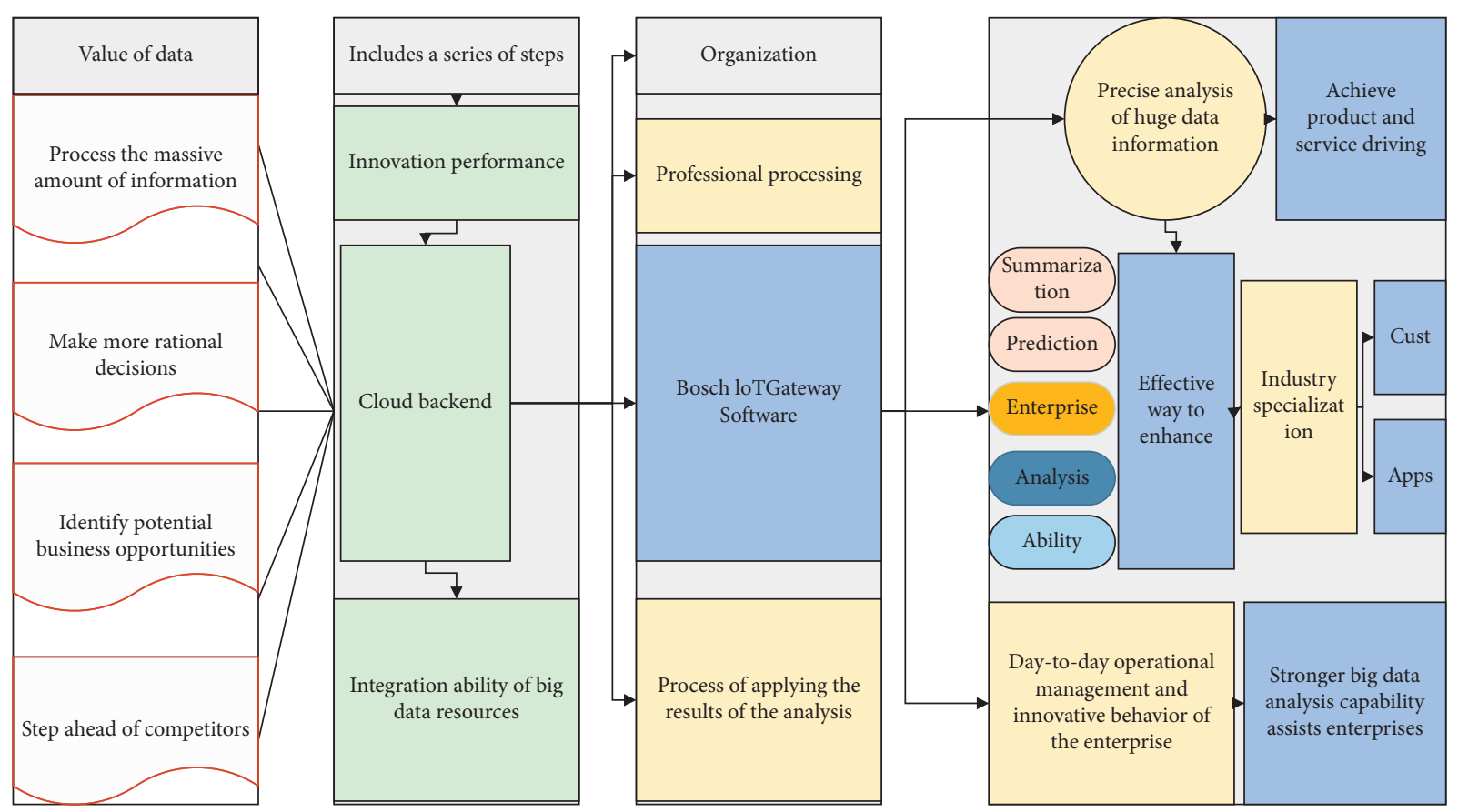

Figure 1: Big data sustainability algorithm design.

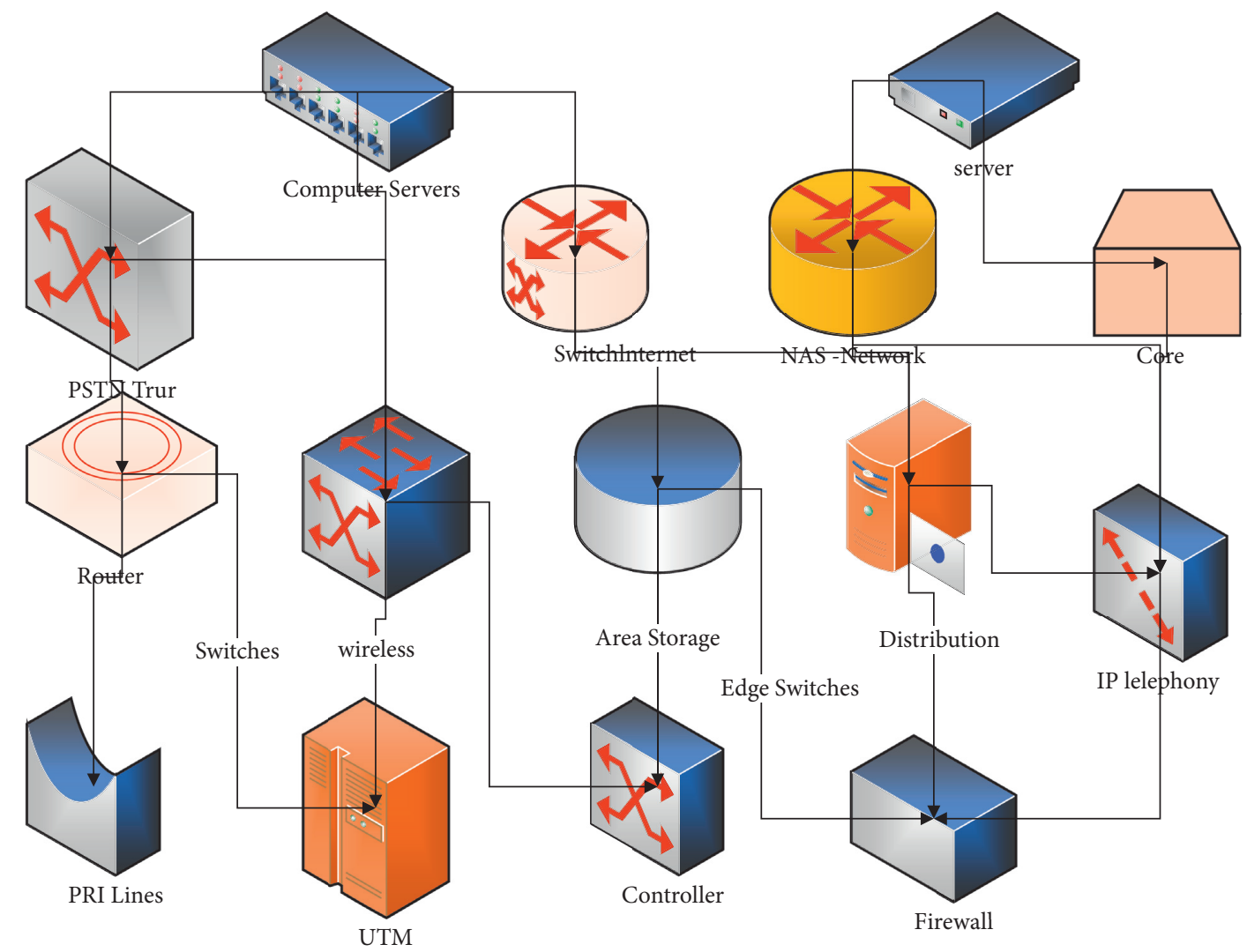

Figure 2: System network architecture diagram.

methods to be scientific and reasonable. Performance evaluation based on the perspective of sustainable development of enterprises can play a supervisory role in the realization of the strategic objectives of enterprises, urging enterprises to arrange various business activities following the requirements of sustainable development culture, as well as a restraint and incentive mechanism, as shown in Figure 3. 
TABLE 1: Indicators for evaluating the status of resource use.

\begin{tabular}{lc}
\hline Index & Meaning \\
$\begin{array}{l}\text { Raw material consumption rate } \\
\begin{array}{l}\text { Ecological cost proportion } \\
\text { Comprehensive utilization of ecological } \\
\text { resources }\end{array}\end{array}$ \\
$\begin{array}{c}\text { The ratio of the total cost of ecological resources consumed in the current period } \\
\text { to the total cost of the current period } \\
\text { per } 10,000 \text { yuan output value }\end{array}$ \\
$\begin{array}{l}\text { The ratio of net profit to the comprehensive cost of ecological resources } \\
\text { The ratio of the consumption of water, electricity, and kerosene in the } \\
\text { production process to the total output value of the enterprise in the current } \\
\text { period }\end{array}$
\end{tabular}

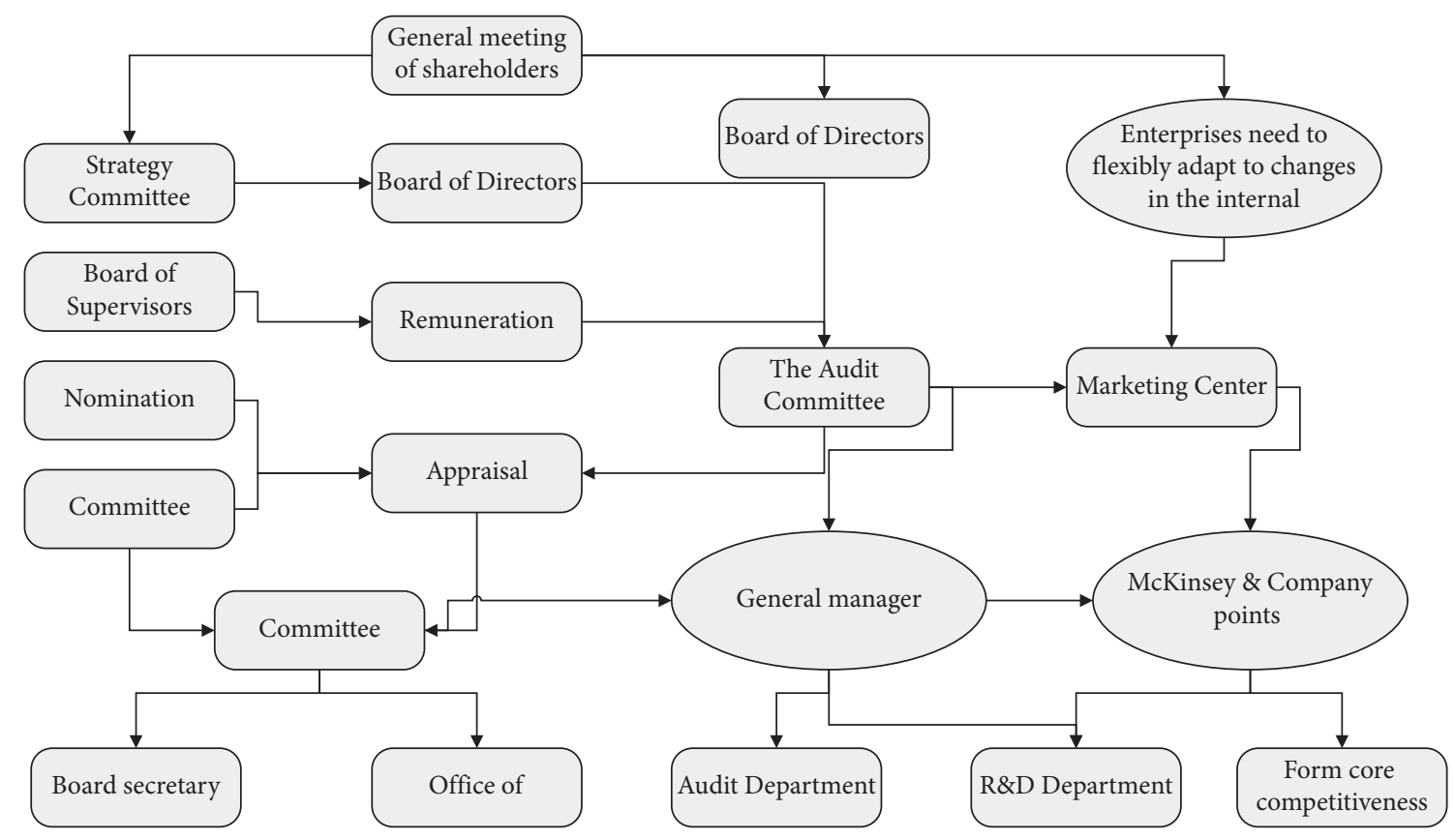

FIGURE 3: Corporate governance structure.

A perfect business performance evaluation system should first have guidelines to be followed in selecting evaluation indicators, and after constructing the evaluation indicator system, appropriate evaluation methods should be used to produce the final evaluation results, and at the same time, relevant systems or organizational measures should be in place to guarantee its smooth implementation, and these elements are indispensable to constitute an organic whole [19]. Mass historical data, potential data mined, combined with the big data system, gradually formed the bank's unified data assets, and gradually strengthen the bank's data-supported business decision-making capabilities. The business performance evaluation system currently implemented by enterprises is too simple in terms of weight setting and should adopt scientific methods; there is no special department responsible for evaluation to take follow-up guarantee measures; the selection of indicators is rather onesided and indicators should be increased or reduced according to the actual business conditions and needs of enterprises, and all aspects of evaluation are too subjective. The ultimate purpose of enterprise business performance evaluation should be to achieve its business strategy objectives, so the business strategy objectives also fundamentally determine the main direction and content of performance evaluation, which is the most basic reference basis for the construction of the evaluation system and will also test and give feedback to the usefulness and effectiveness of the business performance evaluation effect. Therefore, the enterprise business performance evaluation system should first have strategic relevance and be highly consistent with the enterprise development strategy.

Although enterprises have formulated strategies related to sustainable development, they are not performing well except in economic aspects, and negative events happen every year, which shows that the strategies do not guide the operations of enterprises, and the performance evaluation is superficial, with insufficient authority, validity, and credibility to realize the transformation and implementation of strategies. The adoption of a business performance evaluation system based on the perspective of sustainable development of enterprises is in line with the relatively stable and constantly changing strategic objectives set by enterprises, which are continuously adapted to changes in the situation, and can truly play the role of performance 
evaluation in promoting the efficient implementation of corporate development strategies and achieving the guidance of business activities. The corporate strategy covers all aspects of investors, creditors, customers, employees, and social responsibility, but the corporate performance evaluation system cannot respond to the concerns and needs of many stakeholders, including employees, the public, and the government. The current performance evaluation approach is difficult to be recognized by stakeholders, as shown in Figure 4.

The factor loadings of the first public factor in economic growth capacity, capital flow capacity, cost control capacity, and capital structure rationality are $0.828,0.742,0.758$, and 0.638 respectively, which is reflected in the sustainability of its financial dimension; based on this, it can be named as financial sustainability. The goal of any nonpublic good enterprise is to make a profit, and financial sustainability plays a decisive role in the sustainability of the business model of the unmanned economy. The second common factor has factor loadings of $0.801,0.784,0.778$, and 0.703 on effective market capacity, market affinity, market expansion capability, and market resilience, respectively, which reflect the sustainability of the enterprise in the market dimension, and therefore it is named as market sustainability. The market sustainability of the unmanned economy business model affects its market competitiveness and development potential, i.e., it affects the sustainability of its business model [20]. Banks should have deeper and more extensive contact with customers, understand customers, and differentiated analysis of customers, to make more reasonable and diversified allocations of existing resources, so that limited products and resources can meet customers with different needs, and provide better services. Efficient. The third public factor has significant loadings in the ability to provide employment, government support, social compatibility, Internet user size, and resource-saving level, with factor loadings of $0.756,0.725,0.715,0.673$, and 0.559 , respectively, reflecting the sustainability of the unmanned economy business model in the social dimension, hence the name social sustainability. Social support is essential for any business model to be sustainable; therefore, social sustainability is an important factor reflecting the sustainability of the unmanned economy business model. The fourth common factor has large loadings in technological maturity, technological competitiveness, technological innovation, and technological safety, with factor loadings of $0.708,0.632$, 0.617 , and 0.605 respectively, which together reflect the sustainability of the unmanned economy business model in the technological dimension and can be named technological sustainability; from the fact that the unmanned economy business model exhibits "technological equipment instead of human labor,", the strength of technological sustainability is crucial to the sustainability of the business model itself.

\section{Analysis of Results}

4.1. Results of Big Data Analysis. The system should provide $7 \times 24$ hours of continuous operation, with an average

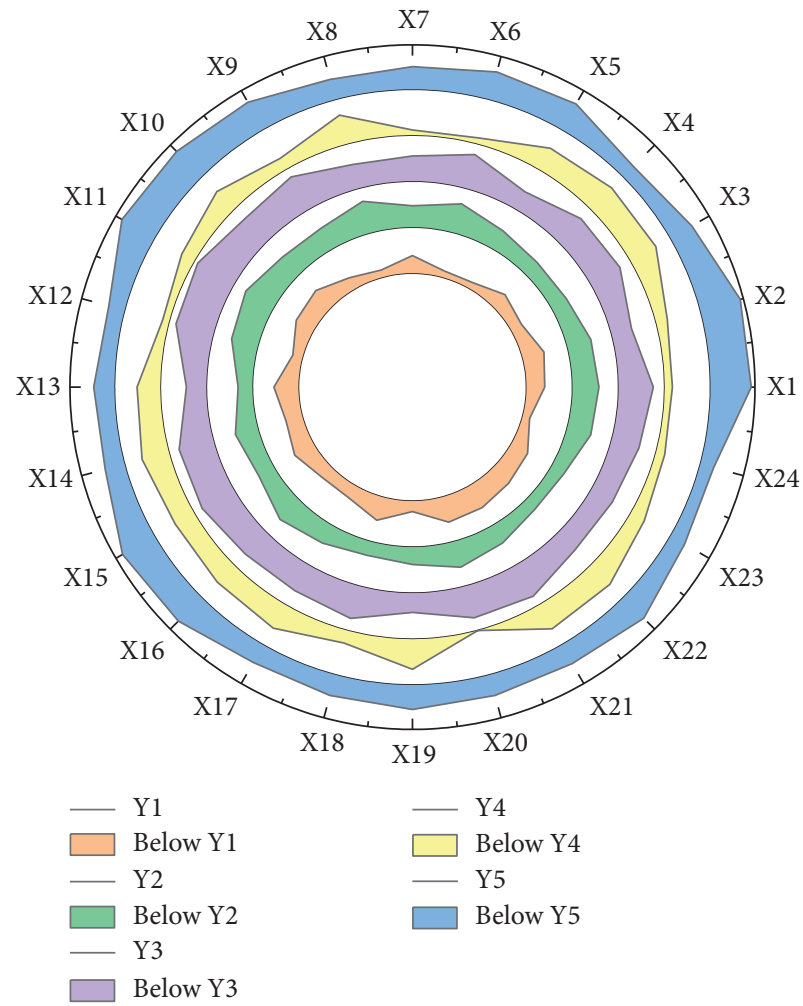

FIgURE 4: Rotation factor loadings.

annual downtime of fewer than 5 days and an average fault repair time of fewer than 8 hours. After the business test is completed, to evaluate the current performance of the system, predict the future performance of the system, and find the bottleneck of the system, etc., the system needs to be tested for performance to ensure that the system can still provide stable services during the peak usage period. Performance testing uses testing tools to simulate multiple users accessing this system concurrently and monitor the server performance. The performance testing tool chosen for the bank's big data precision marketing system is LoadRunner, which records the server response by simulating concurrent access by multiple users, and the results are shown in Table 2 .

From the test results, it can be known that the functions of the Big Data Precision Marketing System meet the Bank's application requirements and the performance meets the Bank's business requirements and can be deployed online. The environmental requirements of this system are introduced, and then the system's functions and performance are tested and validated experimentally, and shown in the form of system screenshots, and the tests of performance are shown in the form of tables, and the results prove that this system meets the business application requirements of our bank. The objective reason is due to the high degree of strategic homogeneity of most of the enterprises and the lack of clear differentiated competitive strategies for target customer groups, product services, channel development, etc.; the enterprises have done a lot of work to improve the sales capacity of front-line account managers, but the market positioning and marketing capabilities led by the head office and branches are relatively weak; in the face of the impact of 
TABLE 2: System performance test results table.

\begin{tabular}{lcc}
\hline Number of connected users & Response time (seconds) & $\begin{array}{c}\text { CPU } \\
\text { usage }\end{array}$ \\
\hline 74 & 0.453628498 & 94.3 \\
51 & 0.287078274 & 91.3 \\
44 & 0.834863213 & 85.5 \\
48 & 0.89722275 & 93.8 \\
69 & 0.13923261 & 84.8 \\
28 & 0.909618373 & 82.8 \\
42 & 0.760454119 & 84.4 \\
\hline
\end{tabular}

Internet finance, the active development of online financial business is still in the initial exploration stage in terms of accurate customer acquisition and personalized recommendation.

The hierarchical analysis method and fuzzy comprehensive evaluation method are suitable for expert scoring; when there are too many levels or indicators, their effectiveness will be reduced, and the method is subject to subjective influence, which will affect the accuracy of evaluation results. The data envelopment analysis method is determined by comparing the input-output ratios of different decision-making units, and the limitations of this method are that a large amount of panel data is required and the structure of the evaluation objects should be the same. A balanced scorecard mainly combines financial and nonfinancial indicators, which include customer, operation, learning, etc. Although it is more comprehensive, it is extremely heavy and costly. The combination of grey correlation and TOPSIS can overcome the shortcomings of each, while reflecting the geometric and dynamical changes between data, and can more accurately evaluate the quality of the program and explain the changes in the program factors and the differences between positive and negative ideal programs, and produce more credible results, as shown in Figure 5. Then, through appropriate marketing strategies and marketing methods to convert customers, you can effectively reduce customer acquisition costs, operating costs, and labor costs.

There are many methods of enterprise performance evaluation, and individual performance evaluation methods inevitably have shortcomings, and there may be differences in the scope of application or different objects of the application. When choosing performance evaluation methods, enterprises should combine different methods with their situation, take the advantage of each method to complement the shortcomings, and maximize the advantages of each method to get the most accurate evaluation results. Through the study of the current situation, it is found that coordination of enterprise performance evaluation content is no longer limited to the financial situation of the enterprise. The coordination industry is increasingly focused on the management of the supply chain, the distance between the various enterprises in the entire supply chain, the assessment of enterprise performance, and on their interests as well as the interests of stakeholders.

The coordination of operational links can greatly improve the efficiency of coordination and enhance the competitiveness of the coordination industry. Therefore, in

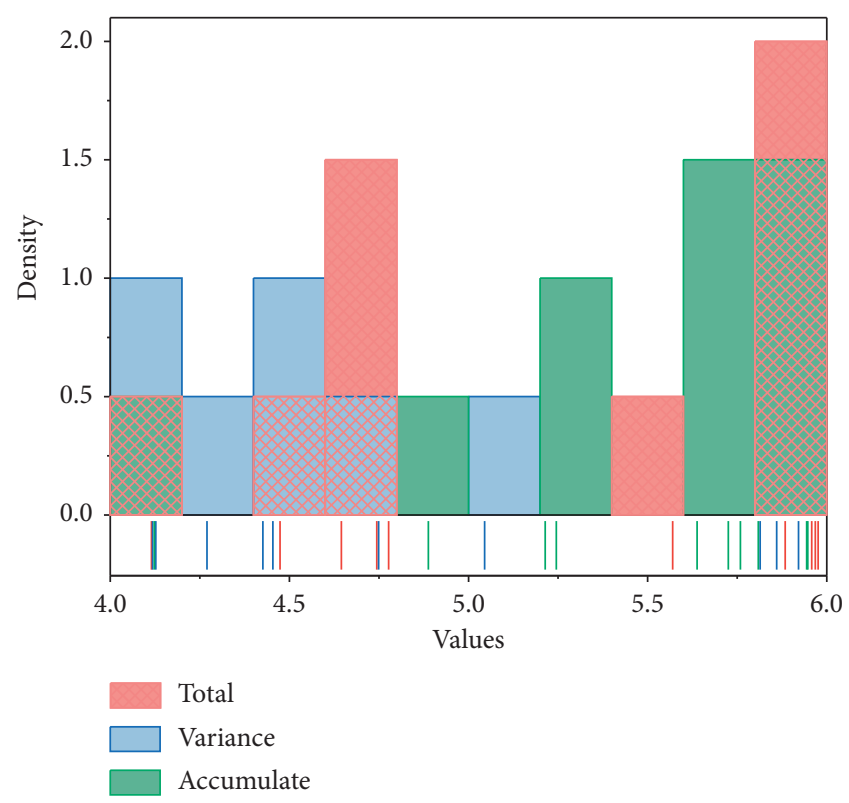

FIgURE 5: Total variance explained.

the evaluation of the performance of coordination enterprises, it is necessary to pay attention to the interests of relevant stakeholders to achieve mutual benefit and a solution where everyone benefits. In addition, coordination enterprises pay more attention to the evaluation of sustainable development aspects in the evaluation. The purpose of enterprise performance evaluation is to find the problems in enterprise management according to the business results and improve the management methods according to the problems to improve the comprehensive level. In the development of enterprise performance evaluation indicators, the sustainable development of enterprises should be considered, and factors such as science and technology, environment, and society should be incorporated into the enterprise performance evaluation indicators according to the concept of sustainable development.

4.2. Experimental Results. Firstness is a measure of uncertainty in information theory; the greater the uncertainty and the lower the firstness, the greater the amount of information contained. Using the qualities of firstness, the dispersion can be expressed in terms of the value of firstness, and the greater the dispersion, which means the greater the value of firstness, the greater the impact on things in a complex evaluation. This will bring huge room for efficiency improvement. By exploring the main factors affecting the sustainability of the unmanned economy business model, discover and reveal the internal influencing mechanism that affects the sustainability of the business model. Therefore, the information fullness can be used as a tool for the comprehensive evaluation of multiple indicators. Unlike other methods, the first value method relies on objective data, which can circumvent the subjective one-sidedness of the artificial assignment method to a certain extent and make the results more objective and scientific. After extensive 


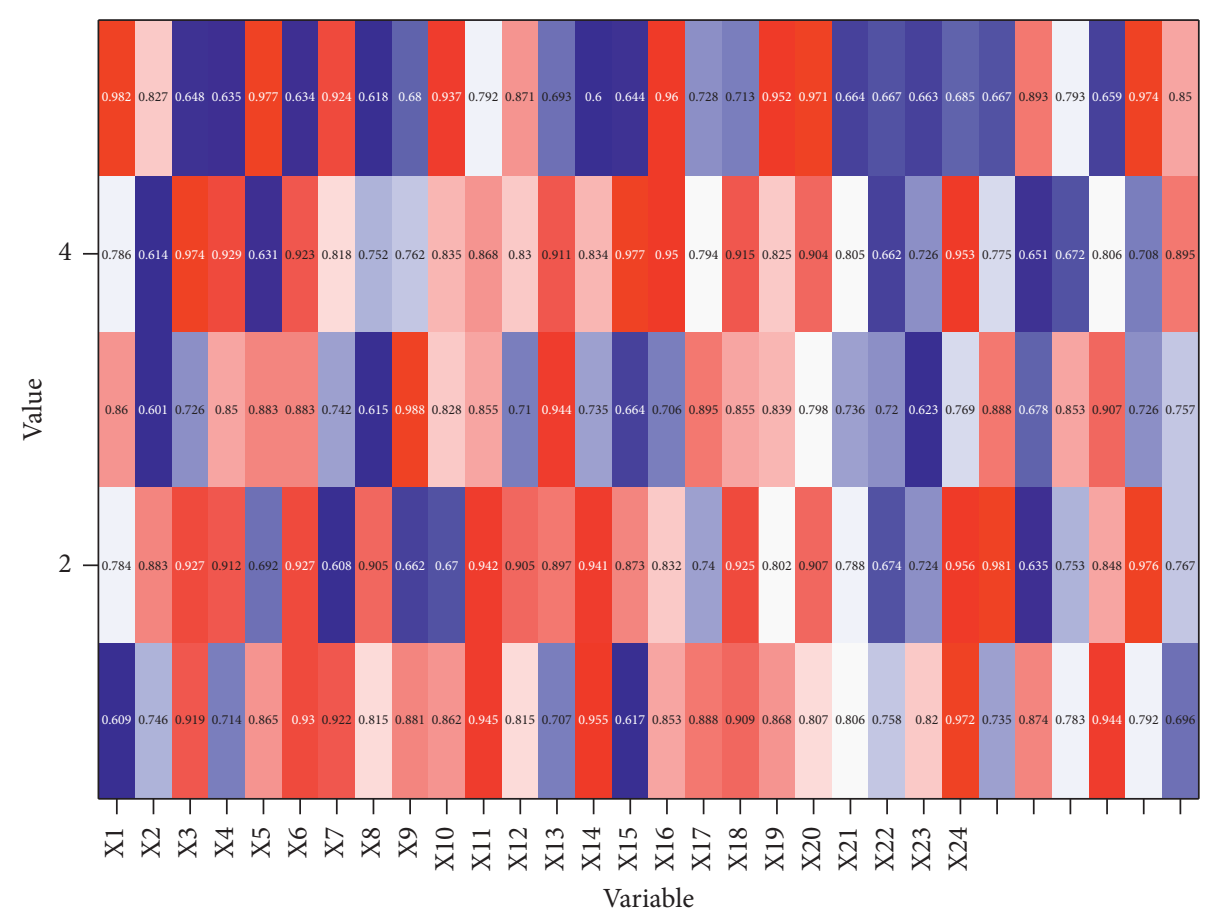

FIGURE 6: Standardization of effectiveness evaluation indicators.

literature and empirical research in different industries, the first value method has obvious applicability and objectivity in the comprehensive evaluation of enterprise business performance. The first value method can be applied to the business performance indicators among different enterprises in the same period, and can also be analyzed for the business conditions of an enterprise in different periods, and the analysis should be selected according to the evaluation purpose and the actual situation of the enterprise, as shown in Figure 6.

The overall level of debt is low, but solvency is not an absolute positive indicator, and too high a solvency indicates that the financing structure of the company is not flexible enough. In debt-servicing capacity, the quick ratio has a large weighting. The enterprise quick ratio, as a moderate indicator, has been in a fluctuating upward trend in the past four years and is higher than the industry quick ratio value range, which shows that the proportion of monetary assets is too large and the efficiency of capital use is not high, and professional institutions should be entrusted to choose a reasonable and reliable financing way for capital management. Improve the customer credit evaluation system, establish a dynamic accounts receivable tracking and analysis system, and entrust professional asset management companies or law firms. It enriches the content of the business performance evaluation system, integrates a variety of measurement factors for corporate sustainable development, provides new perspectives and new angles for China's business performance evaluation system, and promotes the development of related theories. The enterprise scored third in operational capability and performed well. The inventory turnover rate accounts for a large proportion of the operating capacity. In the past four years, the company's inventory turnover rate has been increasing, while the accounts receivable turnover rate has been decreasing. The company has improved the efficiency of inventory turnover by relaxing the accounting period, and the scale of accounts receivable has further increased as the company's business expands while commodities bet into the channel, revenue increases, and the existing accounts receivable has a low recovery rate, difficulty in recovery, and high cost. Because the company's operating cash flow, working capital turnover, and other production and operating activities will be hampered if accounts receivables are not recovered on time, it is not worthwhile to improve the inventory turnover rate and should also be aware of the instability of the drug cycle caused by the shrinking market of public hospitals; the company should begin with channel management and targeted inventory management.

The compact and competent organizational structure provides organizational guarantees for the application of information technology, which in turn provides a convenient and effective space for the enterprise to operate. The inclusion of nonfinancial indicators in the performance evaluation system has placed higher demands on the work of the enterprise and the evaluation team. CP Pharmaceuticals can rely on the Group's software and information technology service companies to improve the original office automation system, make full use of the Internet and big data technology to establish a more comprehensive financial management information platform, coordinate and share the resources of each branch, and systematically manage customer relationships. The company will also make full use of the Internet and big data technology to establish a more comprehensive financial management information platform, coordinate, and share resources among branches, and 


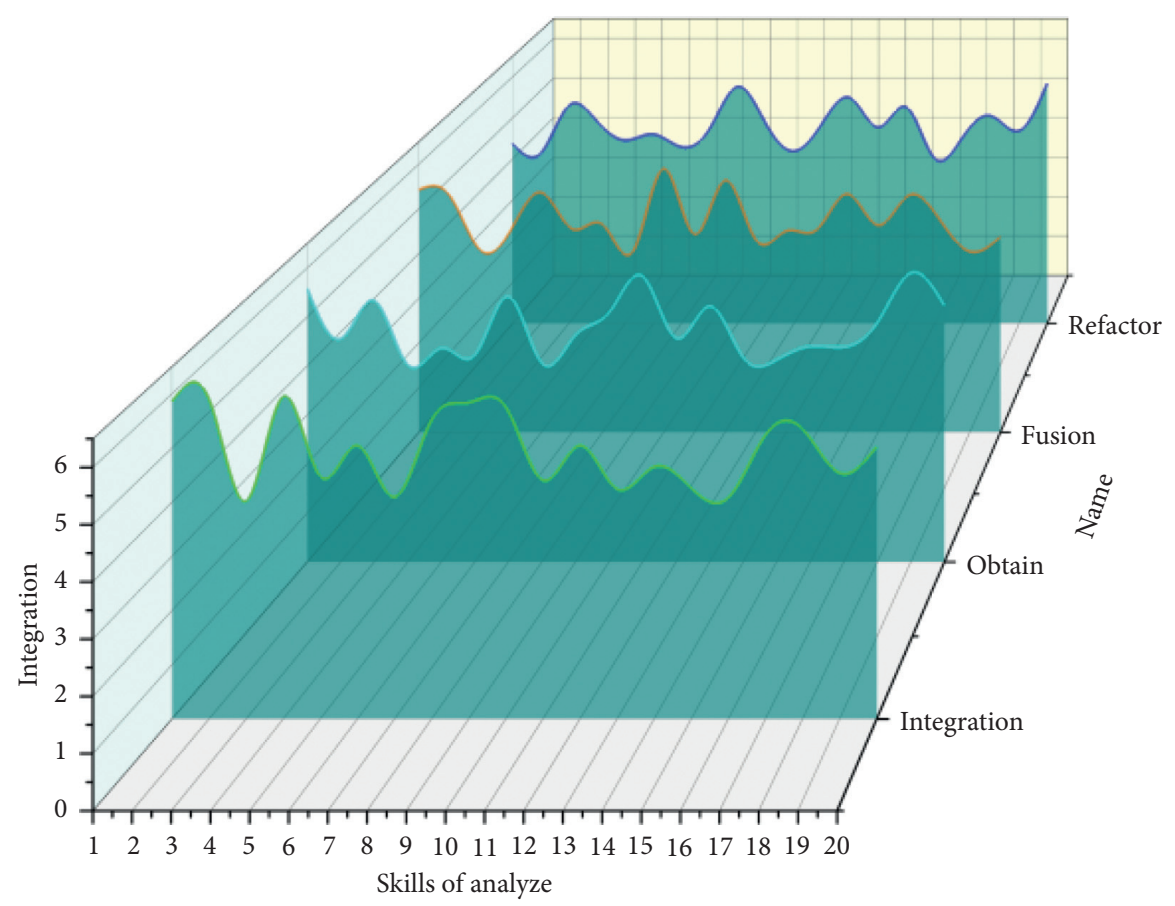

FIGURE 7: Correlation coefficient between big data capabilities and knowledge integration.

systematically manage customer relationships. Complete the connection of various systems in each branch, use intelligent systems to collect and analyze performance management data, and focus on tracking overall performance levels and trends in key indicators. The only thing an enterprise can rely on is often its own dynamic ability to learn and adapt to the environment. Therefore, to gain competitive advantage and respond to the dynamic environment in the era of big data, it is an indispensable requirement to cultivate and build corporate big data capabilities. Maximize the use of the limited resources of the enterprise, and promote a simple and efficient comprehensive evaluation of enterprise performance, as shown in Figure 7.

The system is the basic guarantee for the normal operation of the enterprise, which includes the enterprise management system, staff assessment system, incentive mechanism, etc. System innovation means that the enterprise, with its economic development, constantly adjusts and improves the enterprise system to make it conform to the development of the enterprise and society. Enterprises can keep the radical nature of employees by innovating the management system, changing the internal staff assessment mechanism, and using performance incentives to drive employee creativity, the value of resources to optimize the highest economic advantages of enterprise resources. At present, the establishment of the mining enterprise system should be the main purpose of scientific decision-making and sustainable development, to achieve the optimization of the shareholders' meeting and the board of directors' system, the establishment of a complete modern enterprise system. The core ability to transform the value of data. Big data strategic support capability is the organizational vertical support capability of big data, which refers to the combination of big data planning with its own strategic decision-making, and the strategic positioning of business operations and market development through corresponding big data technology and resources.

\section{Conclusion}

Big data analytics capabilities positively affect the innovation performance of firms. Big data capability is essentially a dynamic capability that can effectively improve the efficiency of all organizational actions in an enterprise. It includes data mining and storage, intelligent analysis and prediction, data product planning, etc. It is a capability that is at the core of big data capability and directly affects the strength of big data capability, which is essentially the ability to dynamically enhance all activities of an enterprise. As data acquisition and analysis become increasingly popular and professional, big data analysis capability can help enterprises to effectively acquire, store, analyze and apply data, take advantage of the benefits brought by data resources, improve the level of information of internal and external organizational processes, aggregate data simulation, realize the business value of big data, and increase the innovative performance of enterprises. It is taken as the overall objective of the evaluation model construction; in response to the identification results of the influencing factors and further systematic analysis of the business model sustainability concept and multi-value pursuit, it is divided into financial sustainability index, market sustainability index, social sustainability index, technology sustainability index, talent sustainability index, and management sustainability index, and these six dimensions are used to construct the unmanned economy business model. Sustainability evaluation index system. This 
is an effective way to improve corporate innovation performance. Secondly, the ability to integrate big data resources is the foundation of big data capabilities. Many mottled and complex data streams cannot generate value for the enterprise but may create a burden instead. The entropy weighting method and the AHP method are combined to assign weights to the indicators, and the index measurement criteria are further combined with the characteristics of the indicators. Finally, based on the results of method comparison and analysis, the fuzzy comprehensive evaluation method is selected to build the sustainability evaluation model.

\section{Data Availability}

The data used to support the findings of this study are included within the article.

\section{Conflicts of Interest}

All the authors do not have any possible conflicts of interest.

\section{Acknowledgments}

This study was supported by "Research on the Cultivation of New Professional Farmers in Jilin Province under the Background of Rural Revitalization (Grant no. ZD19144)”.

\section{References}

[1] C. Liu, Y. Feng, D. Lin, L. Wu, and M. Guo, "Iot based laundry services: an application of big data analytics, intelligent logistics management, and machine learning techniques," International Journal of Production Research, vol. 58, no. 17, pp. 5113-5131, 2020.

[2] A. Ullah, C. Pinglu, S. Ullah, H. S. M. Abbas, and S. Khan, "The role of e-governance in combating COVID-19 and promoting sustainable development: a comparative study of China and Pakistan," Chinese Political Science Review, vol. 6, no. 1, pp. 86-118, 2021.

[3] M. M. Hasan, J. Popp, and J. Oláh, "Current landscape and influence of big data on finance," Journal of Big Data, vol. 7, no. 1, pp. 10-17, 2020.

[4] B. B. Tursunbaevich and Q. S. Axmadjonovich, "Improving management based on the forecast of investment utilization in industrial enterprises," European Journal of Molecular \& Clinical Medicine, vol. 7, no. 7, pp. 809-816, 2020.

[5] I. Ivashkiv, H. Kupalova, N. Goncharenko et al., "Environmental responsibility as a prerequisite for sustainable development of agricultural enterprises," Management Science Letters, vol. 10, no. 13, pp. 2973-2984, 2020.

[6] G. Kaletnik and S. Lutkovska, "Innovative environmental strategy for sustainable development," European Journal of Sustainable Development, vol. 9, no. 2, pp. 89-98, 2020.

[7] S. Ilyas, Z. Hu, and K. Wiwattanakornwong, "Unleashing the role of top management and government support in green supply chain management and sustainable development goals," Environmental Science and Pollution Research, vol. 27, no. 8, pp. 8210-8223, 2020.

[8] A. Z. Faroukhi, I. El Alaoui, and Y. Gahi, "Big data monetization throughout big data value chain: a comprehensive review," Journal of Big Data, vol. 7, no. 1, pp. 15-22, 2020.
[9] S. Modgil, S. Gupta, and B. Bhushan, "Building a living economy through modern information decision support systems and UN sustainable development goals," Production Planning \& Control, vol. 31, no. 11-12, pp. 967-987, 2020.

[10] H. Shevtsova, N. Shvets, M. Kramchaninova, and H. Pchelynska, "In search of smart specialization to ensure the sustainable development of the post-conflict territory: the case of the Luhansk region in Ukraine," European Journal of Sustainable Development, vol. 9, no. 2, pp. 512-524, 2020.

[11] Z. Li, H. Guo, A. V. Barenji, W. M. Wang, Y. Guan, and G. Q. Huang, "A sustainable production capability evaluation mechanism based on blockchain, LSTM, analytic hierarchy process for supply chain network," International Journal of Production Research, vol. 58, no. 24, pp. 7399-7419, 2020.

[12] A. A. Kutty, G. M. Abdella, M. Kucukvar, N. C. Onat, and M. Bulu, "A system thinking approach for harmonizing smart and sustainable city initiatives with United Nations sustainable development goals," Sustainable Development, vol. 28, no. 5, pp. 1347-1365, 2020.

[13] Z. Cheng, H. Wang, W. Xiong, D. Zhu, and L. Cheng, "Publicprivate partnership as a driver of sustainable development: toward a conceptual framework of sustainability-oriented PPP," Environment, Development and Sustainability, vol. 23, no. 1, pp. 1043-1063, 2021.

[14] Z. Salih Ageed, S. Zeebaree, M. Mohammed Sadeeq et al., "A survey of data mining implementation in smart city applications," Qubahan Academic Journal, vol. 1, no. 2, pp. 91-99, 2021.

[15] M. T. Méndez-Picazo, M. A. Galindo-Martín, and M. S. Castaño-Martínez, "Effects of sociocultural and economic factors on social entrepreneurship and sustainable development," Journal of Innovation \& Knowledge, vol. 6, no. 2, pp. 69-77, 2021.

[16] P. F. Borowski, "New technologies and innovative solutions in the development strategies of energy enterprises," HighTech and Innovation Journal, vol. 1, no. 2, pp. 39-58, 2020.

[17] B. Anthony Jnr, S. Abbas Petersen, D. Ahlers, and J. Krogstie, "API deployment for big data management towards sustainable energy prosumption in smart cities-a layered architecture perspective," International Journal of Sustainable Energy, vol. 39, no. 3, pp. 263-289, 2020.

[18] S. Kalogiannidis, "Economic cooperative models: agricultural cooperatives in Greece and the need to modernize their operation for the sustainable development of local societies," International Journal of Academic Research in Business and Social Sciences, vol. 10, no. 11, pp. 452-468, 2020.

[19] G. George, R. K. Merrill, and S. J. D. Schillebeeckx, "Digital sustainability and entrepreneurship: how digital innovations are helping tackle climate change and sustainable development," Entrepreneurship: Theory and Practice, vol. 45, no. 5, pp. 999-1027, 2021.

[20] C.-C. Qi, "Big data management in the mining industry," International Journal of Minerals, Metallurgy and Materials, vol. 27, no. 2, pp. 131-139, 2020. 